\title{
On the Effect of Pre-formed Scales in Mitigating Corrosion of Steels in $\mathrm{CO}_{2}$ Environments
}

\author{
lasonas Zekos ${ }^{1} \cdot$ Kristofer McMeekin ${ }^{1} \cdot$ Margaret M. Stack ${ }^{1}$
}

Received: 22 July 2019 / Revised: 2 March 2020 / Accepted: 12 March 2020 / Published online: 26 March 2020

(C) The Author(s) 2020

\begin{abstract}
Chromium $(\mathrm{Cr})$ containing steels were tested to analyse corrosion behaviour in carbon dioxide saturated water of varying salinities with extended exposure time. Both potentiodynamic and mass loss data were collected to gain a better understanding of the corrosion mechanisms. It was found that both the high $\mathrm{Cr}$ steels displayed degradation in the form of pitting with increasing salinities. However, the low alloy steel reference material showed uniform iron carbonate $\left(\mathrm{FeCO}_{3}\right)$ precipitation. The use of high salinity precipitated layers to aid corrosion protection in lower salinity seawater environments was then established as an interesting area for greater examination. Subsequently, samples of the low alloy steel previously corroded in solutions of 7, 14 and $28 \%$ sodium chloride $(\mathrm{NaCl})$ concentration were then tested in seawater salinities of $3.5 \% \mathrm{NaCl}$. It was found that both the 7 and $14 \% \mathrm{NaCl}$ pre-corroded samples resulted in a significant reduction in the corrosion rate when compared with non-pre-corroded samples. The $7 \% \mathrm{NaCl}$ pre-corroded sample showed the greatest reduction in corrosion rate, and through SEM analysis of the layer both on the surface and cross-section it was found to display an iron carbonate layer more densely packed and defect free. This indicated the potential benefits of high salinity pre-corrosion techniques to aid protection in seawater environments.
\end{abstract}

Keywords Carbon dioxide $\cdot$ Corrosion $\cdot$ Steel $\cdot$ Iron carbonate $\cdot$ Carbonic

\section{Introduction}

Corrosion can be defined as the degradation of a material by its environment [1]. In industry, this degradation can lead to plant inefficiencies, reduction in service life and loss of containment-potentially leading to environmental pollution and loss of life. It has been estimated that the total annual cost of corrosion in the U.S. for the oil and gas industry alone to be $\$ 1.372$ billion. This figure was broken down into $\$ 589$ million for surface pipeline and facility costs, $\$ 463$ million for down hole tubing expenses and $\$ 320$ million in other corrosion related expenditures [2]. A large proportion of this is due to the harsh saline environments encountered by oilfield pipelines which contain corrosion promoting chemical compounds-most notably carbon dioxide $\left(\mathrm{CO}_{2}\right)$ and hydrogen sulphide $\left(\mathrm{H}_{2} \mathrm{~S}\right)$ [3].

Iasonas Zekos

iasonas.zekos@strath.ac.uk

1 Department of Mechanical and Aerospace Engineering, University of Strathclyde, James Weir Building, 75 Montrose Street, Glasgow G1 1XJ, UK
This paper will focus on the presence of $\mathrm{CO}_{2}$ in water. $\mathrm{CO}_{2}$ can be found naturally dissolved in hydrocarbon reservoirs and is also extensively used for enhanced oil recovery (EOR) to improve well productivity [4]. Thus, it is of great importance to understand the corrosion mechanism associated with it.

In the 1940s, recommended guidelines by the American Petroleum Institute (API) [5]—following a joint research venture with Natural Gasoline Association of America (NGAA) and the National Association of Corrosion Engineers (NACE) - were set following $\mathrm{CO}_{2}$ induced failures [6, 7].

The unpredictability and volatility of this corrosion mechanism was highlighted by Bilhartz [8] who showed rapid initiation and through wall penetration of pipelines over a period of 9 months after previous unaffected operations for $10-15$ years.

For carbonic corrosion to take place, carbonic acidformed as $\mathrm{CO}_{2}$ dissociates in water-adsorbs to the metal surface and reacts-as discussed by de Waard et al. [9]. The slow hydration of $\mathrm{CO}_{2}$ was considered by de Waard et al. as the most crucial stage for determining corrosion rate. 
When the concentration of iron ions $\left(\mathrm{F}^{2+}\right)$ and carbonate ions $\left(\mathrm{CO}_{3}{ }^{2-}\right)$ in the water exceed the solubility product limit $\left(\mathrm{KspFeCO}_{3}\right)$ during $\mathrm{CO}_{2}$ corrosion the formation of iron carbonate $\left(\mathrm{FeCO}_{3}\right)$ scale occurs-as described by Nafday and Nesic [10]. The $\mathrm{KspFeCO}_{3}$ can be linked to supersaturation (SS) by the following equation:

$\mathrm{SS}=\frac{\left(\mathrm{Fe}^{2+}\right)\left(\mathrm{CO}_{3}^{2-}\right)}{\mathrm{KspFeCO}_{3}}$

Their work states that $\mathrm{FeCO}_{3}$ scale can only be produced when this supersaturation occurs. The accumulation of this insoluble corrosion product provides protective qualities, promoting passivity as found by Videm and Dugstad [11].

Studies have been conducted by Nesic and Lee which looked at the role of $\mathrm{pH}$, temperature, $\mathrm{CO}_{2}$ partial pressure and the concentration of $\mathrm{F}^{2+}$ ions in the corrosion behaviour of mild steel [12].

This paper will look to expand the understanding of the role of environmental modification by studying the effects of salinity changes on corrosion behaviour in terms of corrosion rate and $\mathrm{FeCO}_{3}$ layer properties. This paper will also look at the viability of initiating the $\mathrm{FeCO}_{3}$ formation on a metal surface in high salinity $\mathrm{CO}_{2}$ solutions to provide corrosion protection in a lower salinity environment.

\section{Experimental}

\subsection{Experimental Conditions and Methodology}

Seven salinities were used to study their effect on corrosion behaviour in $\mathrm{CO}_{2}$ water for the following purposes shown in Table 1.

Water at room temperature $\left(20{ }^{\circ} \mathrm{C}\right)$ was saturated with $\mathrm{CO}_{2}$ according to the protocol and using the apparatus described by Zekos and Stack [13]. 51 of $\mathrm{CO}_{2}$ saturated water are mixed with the predetermined amount of $\mathrm{NaCl}$ in the purged test cell until $\mathrm{NaCl}$ is fully dissolved and then a dissolved oxygen (DO) test using a HI-2400 (Hanna Instruments) dissolved oxygen meter is conducted to ensure that DO concentration is below the $50 \mathrm{ppb}$ threshold and no significant oxygen contamination has occurred. $\mathrm{CO}_{2}$ is

Table 1 Salinity and purpose for testing

\begin{tabular}{ll}
\hline $\mathrm{NaCl}(\%)$ & Purpose \\
\hline 0 & Non-saline baseline for comparison \\
0.16 & Average internal salinity in upstream pipelines \\
0.35 & Analysis of minor salinity increase effects \\
3.5 & Sea water environment simulation \\
$7 / 14 / 28$ & Analysis of high salinity effects
\end{tabular}

injected throughout the test at a volume flowrate of $1.51 / \mathrm{min}$ to ensure an uncontaminated test environment. Conductivity and $\mathrm{pH}$ are measured pre and post- test using a HI9033 conductivity meter (Hanna Instruments) and a HI98103 pH meter (Hanna Instruments), respectively.

\subsection{Test Materials and Preparation}

The following three metal grades commonly used within oilfield pipeline casing and tubing processes were selected for analysis:

UNS G41300 - low carbon steel (LAS).

UNS S41000 - 13\% chromium steel (13Cr).

UNS S41426 - super 13\% Cr steel (S13Cr).

Samples of dimensions $30 \times 30 \times 7.5 \mathrm{~mm}$ were fabricated from pipeline segments manufactured in line with the American Petroleum Institute specifications [14]. The chemical composition of each material can be seen in Table 2.

Samples were polished with a 500 grit silicon carbide polishing paper (Struers). The surface was washed thoroughly with distilled water to remove any existing debris and rinsed with acetone to degrease the surface and ensure no contaminants remained. Samples were hot air dried using a HL1525 heat gun to minimise the onset of flash corrosion. Test specimen mass was measured using a College 150 analytical balance (Mettler) of readability $0.0001 \mathrm{~g}$ and were then stored in a desiccator to inhibit moisture contamination.

\subsection{Test Apparatus}

A three-electrode setup was used as seen in Fig. 1. This consisted of a working, auxiliary and reference electrode (W.E., A.E. and R.E.), represented by the metal sample, platinum coated titanium wire coil and $\mathrm{HI} 5311 \mathrm{Ag} / \mathrm{AgCl}$ electrode (Hanna Instruments), respectively.

Table 2 Chemical composition of studied alloys

\begin{tabular}{llll}
\hline & LCS & $13 \mathrm{Cr}$ & $\mathrm{S} 13 \mathrm{Cr}$ \\
\hline $\mathrm{C}$ & $0.26-0.35$ & $0.15-0.22$ & $\leq 0.03$ \\
$\mathrm{Si}$ & $0.17-0.37$ & $\leq 1.00$ & $\leq 0.50$ \\
$\mathrm{Mn}$ & $0.40-0.70$ & $0.25-1.00$ & $\leq 1.00$ \\
$\mathrm{P}$ & $\leq 0.02$ & $\leq 0.02$ & $\leq 0.02$ \\
$\mathrm{~S}$ & $\leq 0.01$ & $\leq 0.01$ & $\leq 0.005$ \\
$\mathrm{Cr}$ & $0.80-1.10$ & $12.0-14.0$ & $11.5-13.5$ \\
$\mathrm{Ni}$ & $\leq 0.20$ & $\leq 0.20$ & $5.00-6.50$ \\
$\mathrm{Cu}$ & $\leq 0.20$ & $\leq 0.20$ & - \\
$\mathrm{Mo}$ & $0.15-0.25$ & - & $1.50-3.00$ \\
$\mathrm{~V}$ & $\leq 0.08$ & - & $\leq 0.50$ \\
$\mathrm{Al}$ & $\leq 0.02$ & $\leq 0.02$ & - \\
\hline
\end{tabular}


Fig. 1 The corrosion test cell set up schematic

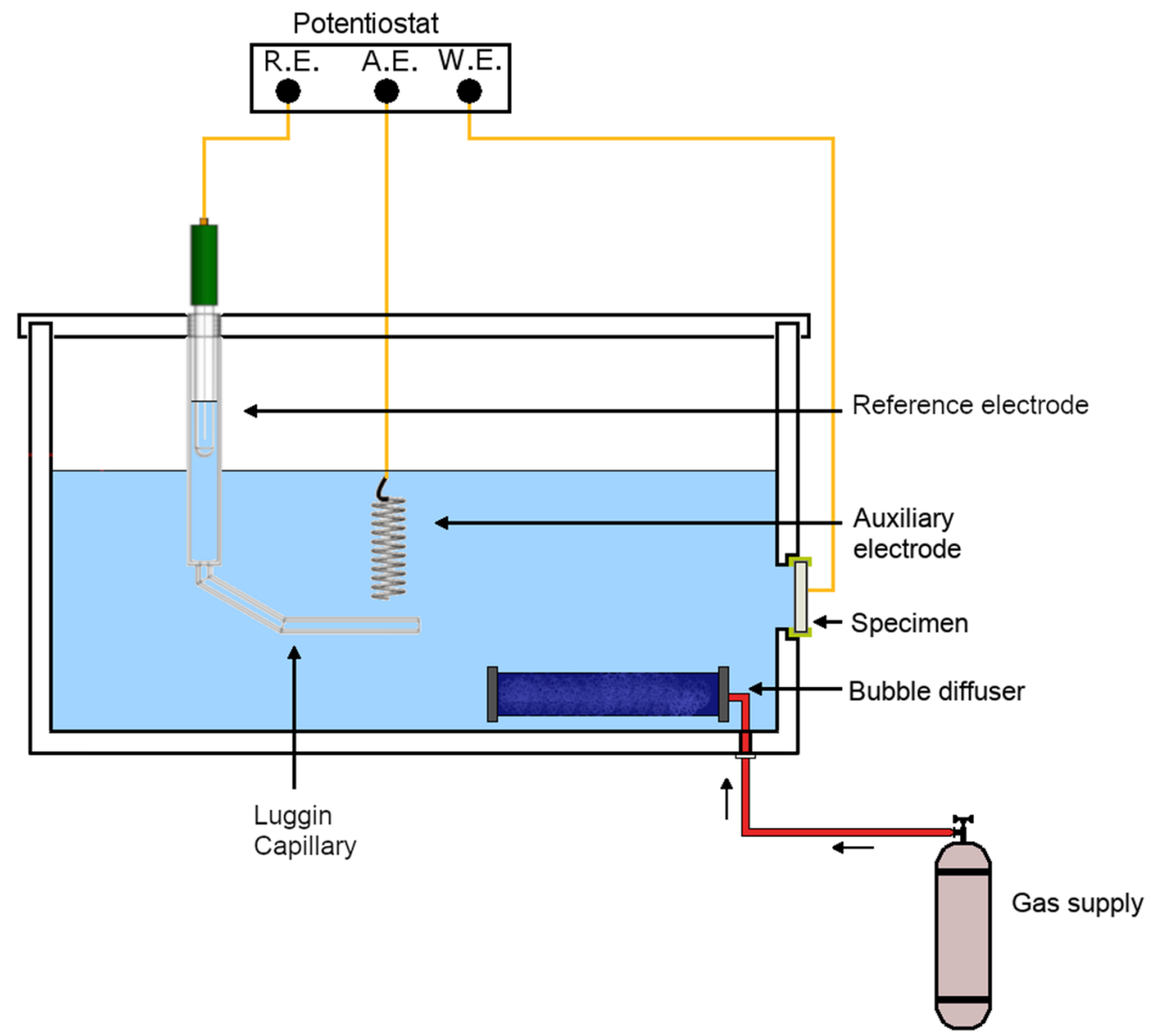

Electrodes were connected to a Gill AC potentiostat (ACM instruments). The test cell was designed and fabricated in house of Perspex.

A lid with air tight entry points provides an air tight seal. The test sample sits in front of an entry hole on the side of the test cell secured by a clamp allowing for only for the designated surface area electrolyte exposure.

A luggin capillary was used with the R.E. to shorten the distance from the W.E. reduce noise and minimise iR drop $[15,16]$.

\subsection{Test Procedure}

A long-term linear polarisation resistance (LPR) sweep test was performed using a sequencer programme (ACM Instruments). This performed 14 non-destructive sweeps from -25 to $+25 \mathrm{mV}$ and a final destructive sweep from -100 to $+1100 \mathrm{mV}$ at intervals indicated in Table 3 .

Non-destructive sweeps were used to evaluate the corrosion rate behaviour with exposure time while the final destructive sweep was utilised to accelerate the effect of corrosion and assess anodic polarisation damage-while comparing
Table 3 Potentiodynamic measurement protocol

\begin{tabular}{lll}
\hline Scan sequence & Time mark (min) & $\begin{array}{l}\text { Scan range } \\
(\mathrm{mV})\end{array}$ \\
\hline 1 & 5 & $(-25)-(+25)$ \\
2 & 30 & $(-25)-(+25)$ \\
3 & 60 & $(-25)-(+25)$ \\
4 & 90 & $(-25)-(+25)$ \\
5 & 120 & $(-25)-(+25)$ \\
6 & 180 & $(-25)-(+25)$ \\
7 & 240 & $(-25)-(+25)$ \\
8 & 300 & $(-25)-(+25)$ \\
9 & 420 & $(-25)-(+25)$ \\
10 & 540 & $(-25)-(+25)$ \\
11 & 660 & $(-25)-(+25)$ \\
12 & 780 & $(-25)-(+25)$ \\
13 & 900 & $(-25)-(+25)$ \\
14 & 1020 & $(-25)-(+25)$ \\
15 & 1140 & $(-100)-(+1100)$ \\
\hline
\end{tabular}

electrochemical and gravimetric corrosion rates obtained. All sweeps were offset around the rest potential (Rp) at the 
recommended scan rate of $10 \mathrm{mV} / \mathrm{min}$ [17]. The total duration of a test sequence was $21 \mathrm{~h}$.

\subsection{Analysis Techniques}

A post-test mass measurement of the sample was taken to obtain gravimetric corrosion rates for comparison with electrochemical results. Scanning electron microscopy (SEM) and energy dispersive X-ray spectroscopy (EDS) analysis techniques were then used to analyse surface morphology and the cross-section of the protective $\mathrm{FeCO}_{3}$ layer.

\subsection{Chemical Reactions of Saline $\mathrm{CO}_{2}$ Corrosion}

Introducing salinity to the water, newly available $\mathrm{Cl}^{-}$ions lead to acceleration of corrosion. This is due to the increase in corrosion product of greater solubility, as compared to less soluble products witnessed in pure water. In high concentrations on the metal surface, $\mathrm{Cl}^{-}$ions along with hydrated regions lead to the formation of iron chloride $\left(\mathrm{FeCl}_{2}\right)$. This in turn leads to hydrolysis and a reduction in the $\mathrm{pH}$ reading of the water [18]:

$\mathrm{FeCl}_{2}+\mathrm{H}_{2} \mathrm{O} \rightarrow \mathrm{FeO}+2 \mathrm{HCl}$

With the introduction of $\mathrm{CO}_{2}$ to the environment, the nature of the corrosion reaction alters. Initially, when $\mathrm{CO}_{2}$ is added to the water it is partly hydrated and forms carbonic acid [19]:

$\mathrm{CO}_{2}+\mathrm{H}_{2} \mathrm{O} \rightleftharpoons \mathrm{H}_{2} \mathrm{CO}_{3}$

Carbonic acid is diprotic, a class of Arrhenius acid. As a result, per molecule it has the ability of donating two protons or hydrogen cations during dissociation in water. This dissociation occurs in the following two steps:

$\mathrm{H}_{2} \mathrm{CO}_{3} \rightleftharpoons \mathrm{H}^{+}+\mathrm{HCO}_{3}^{-}$

$\mathrm{HCO}_{3}^{-} \rightleftharpoons \mathrm{H}^{+}+\mathrm{CO}_{3}^{2-}$

Thus, the carbonic corrosion of steel in this $\mathrm{CO}_{2}$-rich environment takes the form of:

$\mathrm{Fe}+2 \mathrm{H}_{2} \mathrm{CO}_{3} \rightarrow \mathrm{Fe}^{2+}+2 \mathrm{HCO}_{3}^{-}+\mathrm{H}_{2}$

During the ionisation of iron atoms, equal amounts of alkalinity are produced. As a result, the $\mathrm{pH}$ of the solution can be expected to increase throughout the corrosion process. This increase in $\mathrm{pH}$ coupled with the produced $\mathrm{Fe}^{2+}$ and $\mathrm{CO}_{3}{ }^{2-}$ ions concentration reaching the solubility limit allows for the formation of $\mathrm{FeCO}_{3}$ scale:

$\mathrm{Fe}^{2+}+\mathrm{CO}_{3}^{2-} \rightarrow \mathrm{FeCO}_{3}$

\section{Results}

\subsection{Electrochemically Measured Corrosion Progression Over Time}

Non-destructive sweeps were carried out on LAS, $13 \mathrm{Cr}$ and $\mathrm{S} 13 \mathrm{Cr}$ to understand the electrochemical corrosion rate behaviour with exposure time in $\mathrm{CO}_{2}$ saturated water of varying salinities.

As it can be seen in Fig. 2, the average corrosion rate steadily increases as the salinity of the $\mathrm{CO}_{2}$ solution rises from 0 to $0.16,0.35$ and $3.5 \% \mathrm{NaCl}$ reaching a peak corrosion rate of $1.31 \mathrm{~mm} / \mathrm{year}$ at $3.5 \%$ salinity. However, further salinity increases to 7,14 and $28 \%$ cause a reduction in the average measured corrosion rate bringing the corrosion down to $0.7 \mathrm{~mm} /$ year for $28 \%$ which is only slightly greater than the $0.6 \mathrm{~mm} /$ year measured at $0.35 \%$ salinity.

Significant information can be obtained by observing the corrosion rate progression over time. As seen in Fig. 3, the corrosion rate for the $0,0.16$ and $0.35 \%$ salinity remains fairly steady throughout the 1025 mins, but as the salinity increases the corrosion rate trend over time increases as well. The corrosion rate for 3.5, 7 and $14 \%$ undergoes a rapid increase in the first $100 \mathrm{~min}$ and then continues to increase throughout the test duration at a lower rate. In the case of the $7 \%$ salinity solution, the corrosion rate starts at $0.74 \mathrm{~mm} /$ year and after only $100 \mathrm{~min}$ it has reached $1 \mathrm{~mm} /$ year, it then reaches a peak of $1.44 \mathrm{~m} /$ year at the 900 min mark. The same trend is also observed for the $28 \% \mathrm{NaCl}$ solution but the intensity of the increase is significantly lower tends to resemble the steady corrosion rate of $0,0.16$ and $0.35 \% \mathrm{NaCl}$ solutions.

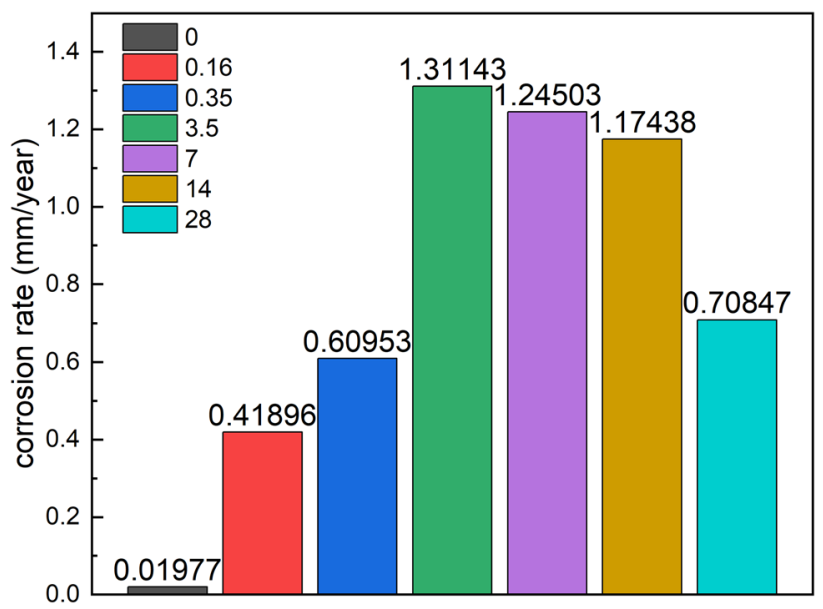

Fig. 2 Average electrochemical corrosion of LAS for $0,0.16,0.35$, $3.5,7,14$ and $28 \% \mathrm{NaCl}$ concentrations in $\mathrm{CO}_{2}$ saturated solution during the first $1025 \mathrm{~min}$ 


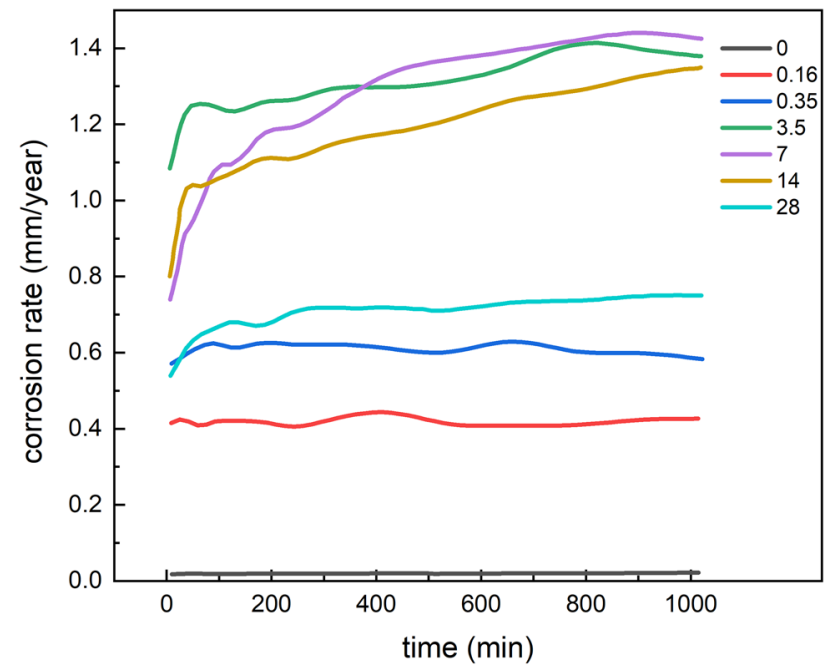

Fig. 3 LAS electrochemical corrosion rate progression over $1025 \mathrm{~min}$ of exposure time for $0,0.16,0.35,3.5,7,14$ and $28 \% \mathrm{NaCl}$ concentrations in $\mathrm{CO}_{2}$ saturated solution

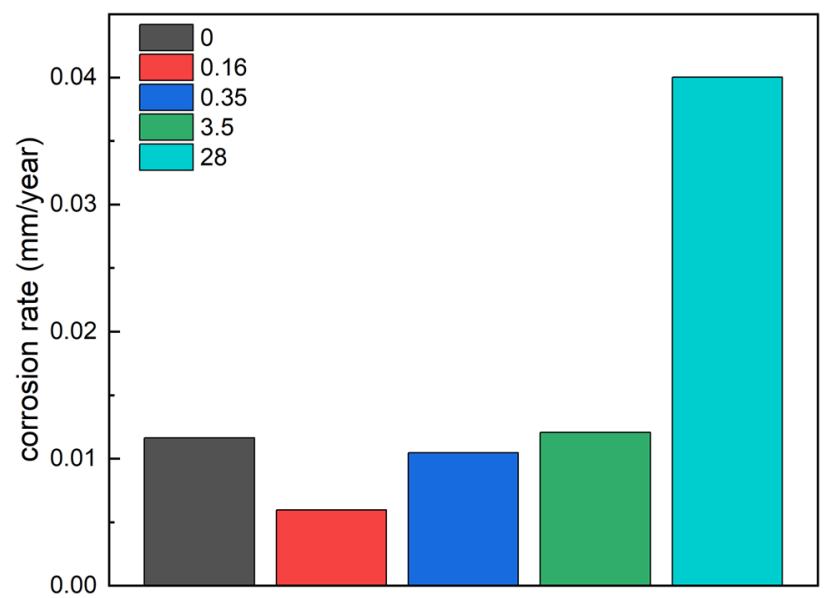

Fig. 4 Average electrochemical corrosion of $13 \mathrm{Cr}$ for $0,0.16,0.35$, 3.5 and $28 \% \mathrm{NaCl}$ concentrations in $\mathrm{CO}_{2}$ saturated solution during the first $1025 \mathrm{~min}$

Unexpectedly, as seen in Fig. 4, the non saline solution produced an average corrosion of $0.011 \mathrm{~mm} /$ year for $13 \mathrm{Cr}$, which is greater than those observed in the 0.16 and $0.35 \%$ salinity solutions and very close to the $0.012 \mathrm{~mm} /$ year corrosion rate of the $3.5 \%$ salinity solution. Despite that inconsistency the rest of the results appear to follow the expected trend of increased salinity resulting to increased corrosion rate with a maximum corrosion rate average of $0.04 \mathrm{~mm} / \mathrm{year}$ achieved for the $28 \%$ salinity solution.

The corrosion rate progression trends for $13 \mathrm{Cr}$ seen in Fig. 5 are quite different from those seen for LAS. The corrosion rate of $13 \mathrm{Cr}$ in all solutions starts high and drops over time. The corrosion rate in the solutions with $0.16,0.35$,

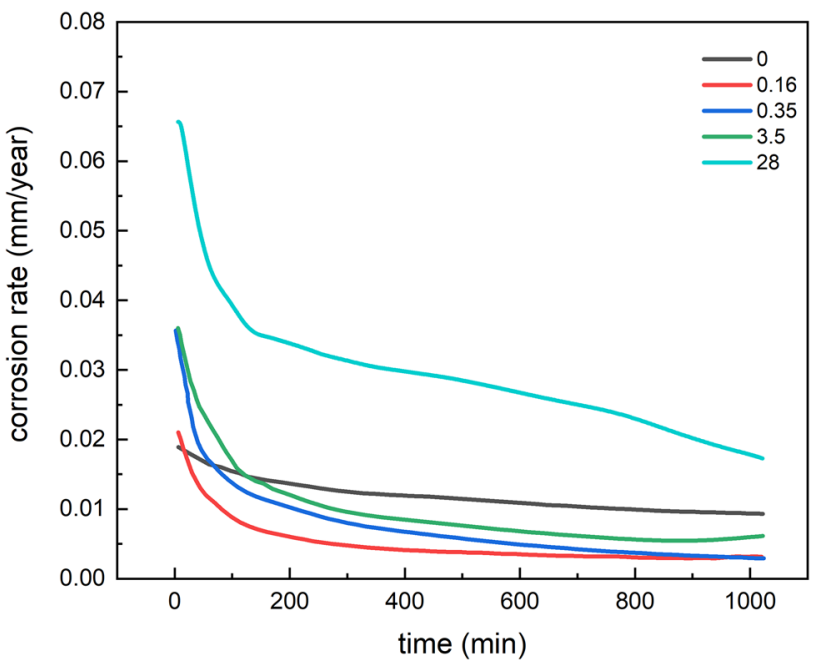

Fig. $513 \mathrm{Cr}$ electrochemical corrosion rate progression over 1025 min of exposure time for $0,0.16,0.35,3.5$ and $28 \% \mathrm{NaCl}$ concentrations in $\mathrm{CO}_{2}$ saturated solution

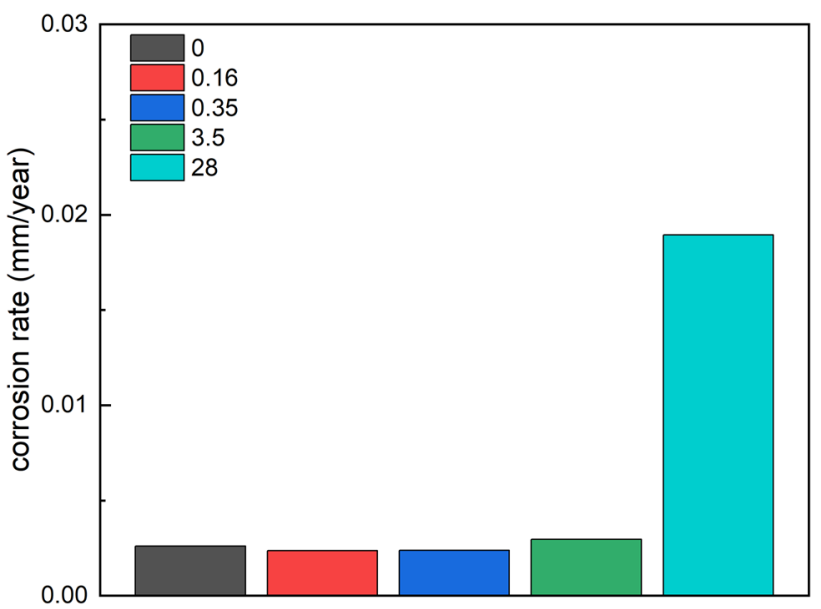

Fig. 6 Average electrochemical corrosion of $\mathrm{S} 13 \mathrm{Cr}$ for $0,0.16,0.35$, 3.5 and $28 \% \mathrm{NaCl}$ concentrations in $\mathrm{CO}_{2}$ saturated solution during the first $1025 \mathrm{~min}$

3.5 and $28 \%$ salinity exhibits rapid decrease within the first $150 \mathrm{~min}$ of tests and then the reduction slowly tapers off, whereas in the case of the non saline solution the corrosion rate reduction is much more gentle. As an example, the corrosion rate of the $28 \%$ salinity stasts at $0.065 \mathrm{~mm} /$ year and after $1025 \mathrm{~min}$ it goes down to $0.017 \mathrm{~mm} /$ year whereas in the saline-free solution the corrosion rate starts at $0.018 \mathrm{~mm} /$ year and it goes down to $0.009 \mathrm{~mm} /$ year. The starting corrosion rate value of the saline-free solution is the lowest recorded but as the corrosion rate in the other solutions exhibits rapid decrease at the 1025 min mark its corrosion rate is greater than that of $0.16,0.35$ and $3.5 \%$ $\mathrm{NaCl}$ solutions. 
In the case of $\mathrm{S} 13 \mathrm{Cr}$ as seen in Fig. 6 the average corrosion rate for the $0,0.16$ and $0.35 \%$ salinity solutions do not present any observable differences. The increase of salinity to $0.35 \%$ only causes a minute increase in corrosion rate of $0.0006 \mathrm{~mm} /$ year but there was a significant increase in corrosion rate to $0.019 \mathrm{~mm} /$ year when the salinity was increased to $28 \%$.

The corrosion rate progression over time for the $0,0.16$, 0.35 and $3.5 \%$ salinity solutions, seen in Fig. 7 , follows the same trend observed for $13 \mathrm{Cr}$. There is initially a high corrosion rate which rapidly decreases in the first $150 \mathrm{~min}$ and then continues to decrease in a smoother rate. As it was the case with the corrosion rate average, the curves of 0 , 0.16 and 0.35 do not have any discernible differences but

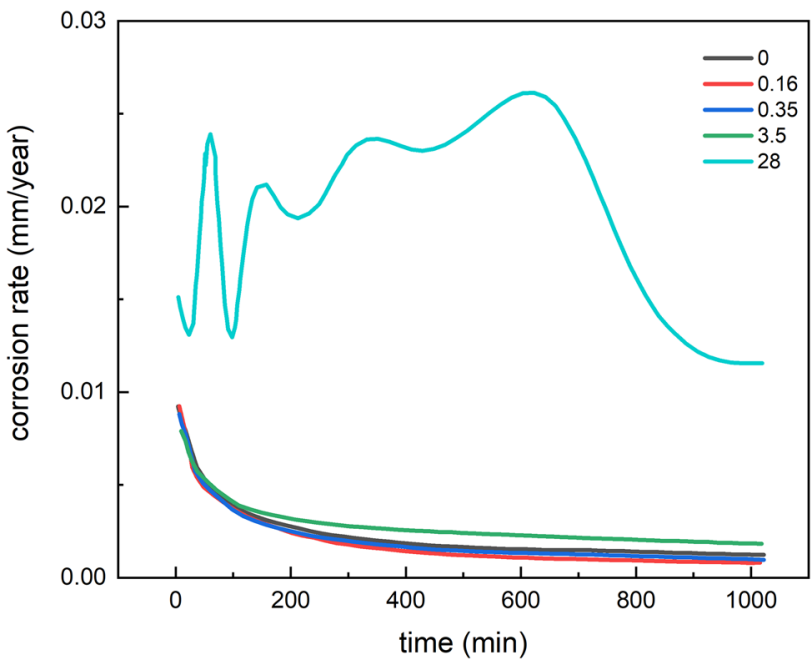

Fig. $7 \mathrm{~S} 13 \mathrm{Cr}$ electrochemical corrosion rate progression over 1025 min of exposure time for $0,0.16,0.35,3.5$ and $28 \% \mathrm{NaCl}$ concentrations in $\mathrm{CO}_{2}$ saturated solution the curve of $3.5 \%$ salinity although it starts at the same level as the others it does not decrease to the same degree. The curve of $28 \%$ salinity does not follow the same trend as the others, there are constant fluctuation with the corrosion rate starting at $0.015 \mathrm{~mm} /$ year, reaching a peak of $0.026 \mathrm{~mm} /$ year after $623 \mathrm{~min}$ and finally dropping down to $0.011 \mathrm{~mm} /$ year.

\subsection{Comparison of Electrochemical Corrosion Rate to Gravimetric Corrosion Rate}

In this section, mass loss measurements of the specimens transformed to corrosion rate values are compared to the corrosion rate measurements obtained from the final longrange destructive LPR sweep.

As seen in Fig. 8 there is an increase in the electrochemical corrosion rate which appears to be relatively proportional to the salinity increase up until $14 \%$. Salinity here, much like in the non-destructive tests, enhances corrosion up to a point and then further salinity increase causes a reduction in corrosion; however, in the destructive tests the salinity effect on corrosion peaks at higher salinity of $14 \%$ compared to $3.5 \%$ for non-destructive tests. The same effect is also observed on the gravimetric corrosion rate as well; however the values of the electrochemical corrosion rate are significantly lower compared to the gravimetric ones throughout the range of tested salinities.

The electrochemical and gravimetric corrosion rates of $13 \mathrm{Cr}$ are a lot more consistent compared to LAS for the majority of the salinities. Surprisingly, the superior chemical composition of $13 \mathrm{Cr}$ has only negated the effects of corrosion in the low salinity tests of $0,0.16$ and $0.35 \%$ salinity, whereas for 3.5 and $28 \%$ salinity, both the electrochemical and gravimetric corrosion rates of $13 \mathrm{Cr}$ were higher than the equivalent values for LAS.
Fig. 8 Electrochemical corrosion rate vs. Gravimetric corrosion rate for $\mathrm{LAS}, 13 \mathrm{Cr}$ and $\mathrm{S} 13 \mathrm{Cr}$ at varying salinities

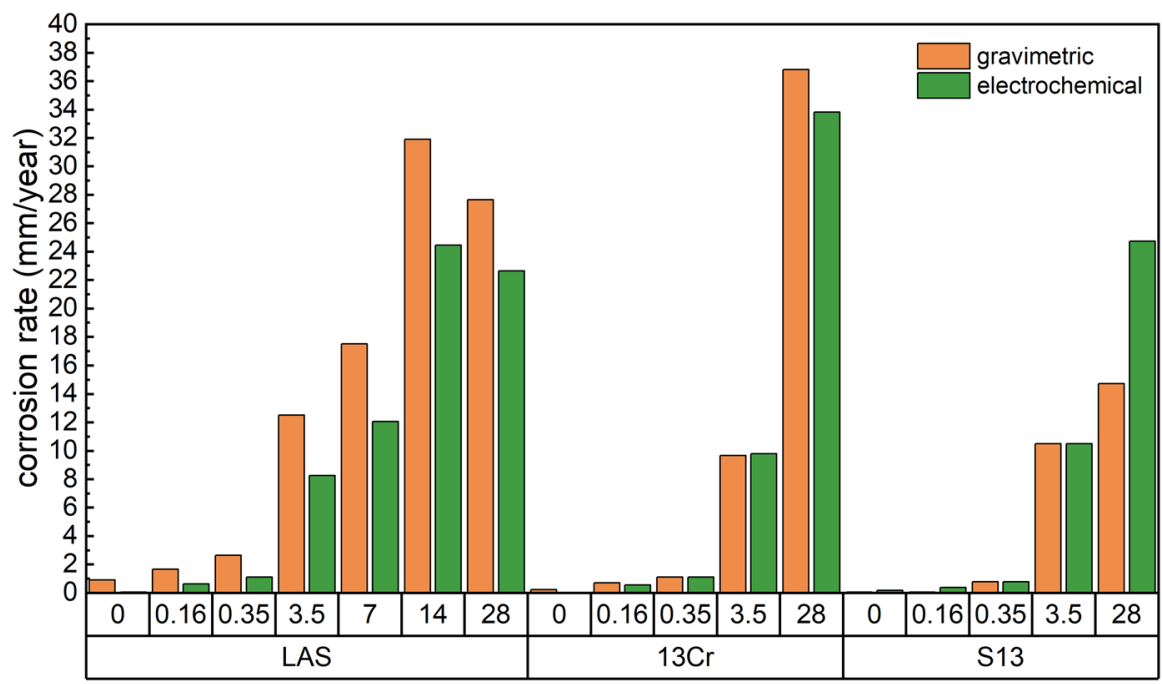




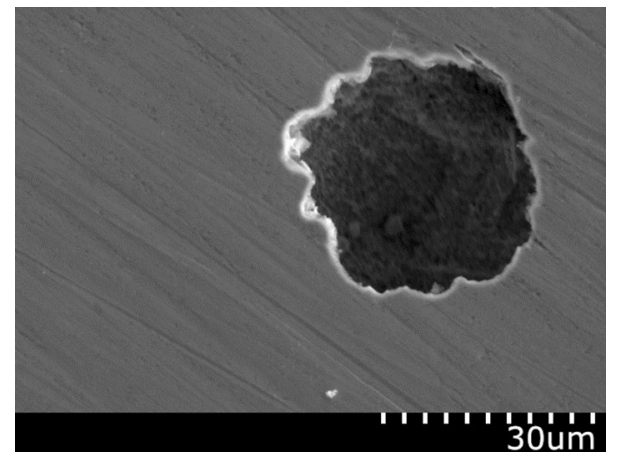

Fig. 9 Pitting on the surface of $13 \mathrm{Cr}$ at $0 \% \mathrm{NaCl} \mathrm{CO}_{2}$ solution

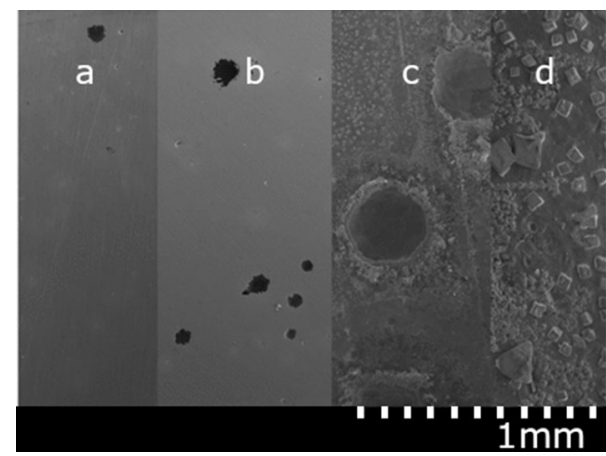

Fig. 10 Surface morphology of $13 \mathrm{Cr}$ at $0 \%$ (a), $0.16 \%$ (b), $0.35 \%$ (c), $3.5 \%(\mathbf{d})$ and $28 \% \mathrm{NaCl}(\mathbf{e})$

The even nobler $\mathrm{S} 13 \mathrm{Cr}$ presents slightly lower corrosion rates compared to $13 \mathrm{Cr}$ for $0,0.16$ and $0.35 \%$ salinity and a significant decrease for $28 \%$ salinity where there was a considerable discrepancy between electrochemical and gravimetric corrosion rates. The electrochemical corrosion rate of $\mathrm{S} 13 \mathrm{Cr}$ in the $3.5 \%$ salinity solution is the greatest recorded followed by $13 \mathrm{Cr}$ and finally LAS whereas the gravimetric corrosion rate of LAS is significantly higher than those of $\mathrm{S} 13 \mathrm{Cr}$ and $13 \mathrm{Cr}$ in the same environment.

\subsection{Surface Morphology and Composition}

It was seen for both $13 \mathrm{Cr}$ and $\mathrm{S} 13 \mathrm{Cr}$ that pitting had occurred on the surface. EDS analysis highlighted the presence of chromium oxide $\left(\mathrm{Cr}_{2} \mathrm{O}_{3}\right)$ and $\mathrm{Cl}$ which aided the opinion that the pitting witnessed was due to this protective chromium oxide layer breakdown in localised regions.

Initially the size and concentration of pitting at $0 \% \mathrm{NaCl}$ for both materials is negligible An example of the scarce minute pits can been in Fig. 9 under $\times 1.5 \mathrm{k}$ magnification of pitting was increased for both $13 \mathrm{Cr}$ and $\mathrm{S} 13 \mathrm{Cr}-$ Figs. 10 and 11 , respectively-as a result of growing $\mathrm{Cl}^{-}$ion concentration supplied by increasing salinities. For $13 \mathrm{Cr}$, this

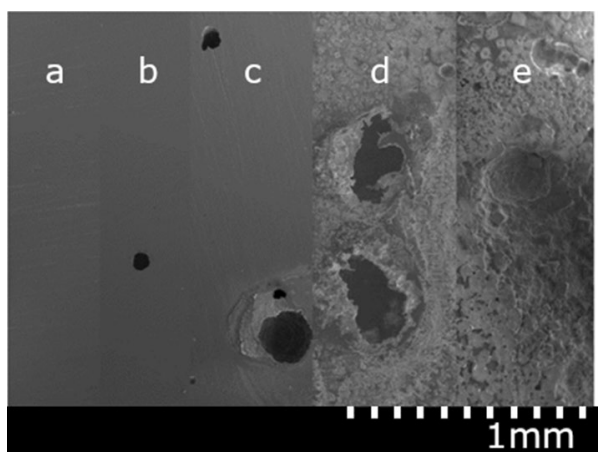

Fig. 11 Surface morphology of $\mathrm{S} 13 \mathrm{Cr}$ at $0 \%$ (a), $0.16 \%$ (b), $0.35 \%$ (c), $3.5 \%$ (d) and $28 \% \mathrm{NaCl}(\mathbf{e})$

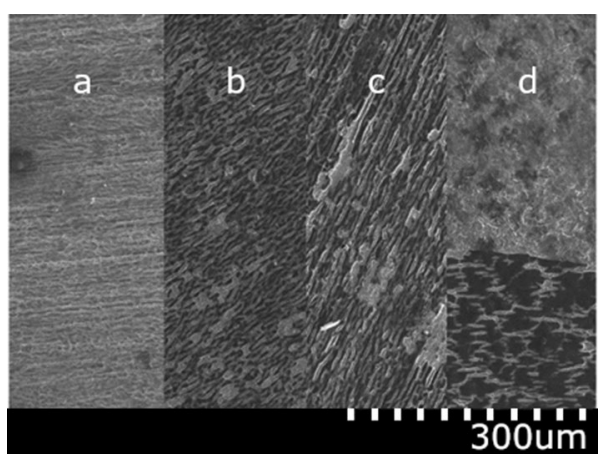

Fig. 12 Surface morphology of LAS at $0 \%$ (a), $0.16 \%$ (b), $0.35 \%$ (c) and $3.5 \% \mathrm{NaCl}$ (d)

agrees with the findings by $\mathrm{Li}$ et al. [20]. Which found high $\mathrm{Cl}^{-}$concentration resulted in $13 \mathrm{Cr}$ being susceptible to pitting.

LAS showed dark uniform precipitate formed on the exposed surface in the form of $\mathrm{FeCO}_{3}$. As shown previously this resulted in high discrepancies between the corrosion rate witnessed by both gravimetric and electrochemically obtained corrosion rates.

The $\mathrm{FeCO}_{3}$ layer was therefore studied further to ascertain its potential as a corrosion inhibitor. SEM analysis was carried out to analyse the surface morphology of the $\mathrm{FeCO}_{3}$ produced at all salinities as shown in Figs. 12 and 13.

At $0 \% \mathrm{NaCl}$ a new layer is beginning to form on the surface of an established layer. Evidence of that new layer can be seen at the bottom of Fig. 12a in the form of a darker platelet. The established layer morphology shows high concentration of layer cracks.

As the salinity increases to $0.16 \% \mathrm{NaCl}$, the sample is now predominately covered by a protective layer confirmed by EDS to be $\mathrm{FeCO}_{3}$. As seen in Fig. 12b, the oxide layer surface is filed with wide cracks throughout.

As seen in Fig. 12c, a further increase in salinity to $0.35 \%$ results in a secondary protective layer (light grey 


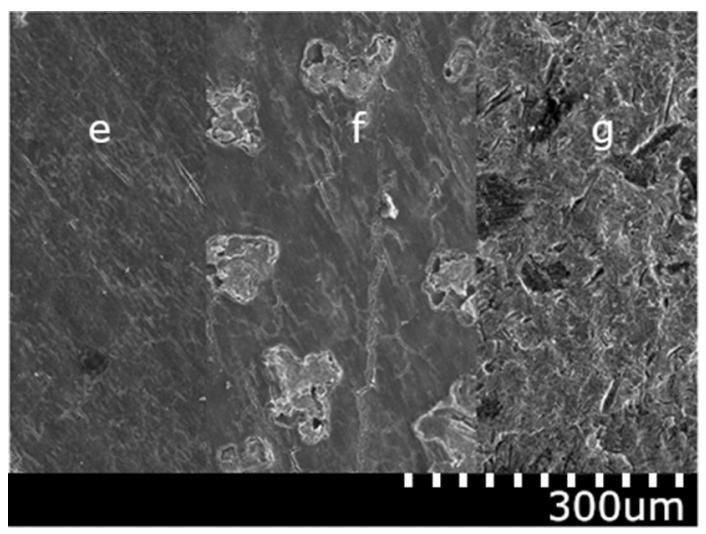

Fig. 13 Surface morphology of LAS at 7\% (e), 14\% (f), and 28\% $\mathrm{NaCl}(\mathbf{g})$

platelets) with much larger plates forming on top of the existing $\mathrm{FeCO}_{3}$ layer. However, the coverage of the secondary $\mathrm{FeCO}_{3}$ layer is poor leaving much of the substrate exposed. The oxide layer's morphology appears improved over the ones witnessed at 0 and $0.16 \% \mathrm{NaCl}$ with a lower concentration of cracks.

At $3.5 \% \mathrm{NaCl}$ the new precipitate forming on the established $\mathrm{FeCO}_{3}$ layer is fairly uniform with little observable cracking, leaving very little of the sublayer exposed as it can be clearly seen at the upper half of Fig. 12d. In order to get a better look at the sublayer, the top layer was carefully removed using a cotton bud soaked in deionised water. The exposed sub layer seen at the bottom half of Fig. 12d, displays a low concentration of cracks.

It is clear for $7 \% \mathrm{NaCl}$ (Fig. 13e) that a much denser and compact top layer of $\mathrm{FeCO}_{3}$ has formed. There are no major gaps between plate boundaries compared to the $\mathrm{FeCO}_{3}$ layer for $3.5 \% \mathrm{NaCl}$.

When salinity is doubled to $14 \% \mathrm{NaCl}$, as seen in Fig. 13f, the protective $\mathrm{FeCO}_{3}$ layer shows signs of localised degradation in the form of cracks and flaking of platelets indicated by the lighter grey areas. This is unfavourable as it will result in pockets of high concentration of $\mathrm{Cl}^{-}$which may further aid layer breakdown through to sub-surface and subsequently into the metal at a localised point. This has been confirmed by EDS analysis which has picked up the presence of $\mathrm{Cl}$ which was not in lower salinity samples.

For the highest salinity of $28 \% \mathrm{NaCl}$ (Fig. $13 \mathrm{~g}$ ) the surface is cluttered with cracks and appears to be more porous. Areas of top and sub-surface $\mathrm{FeCO}_{3}$ appear together much more frequently, as opposed to defined areas of sub layer and new top layer as seen for lower salinities. EDS analysis confirms both the layers to be $\mathrm{FeCO}_{3}$. Also, EDS in the sub-surface demonstrated high concentrations of iron, chromium and oxygen which show

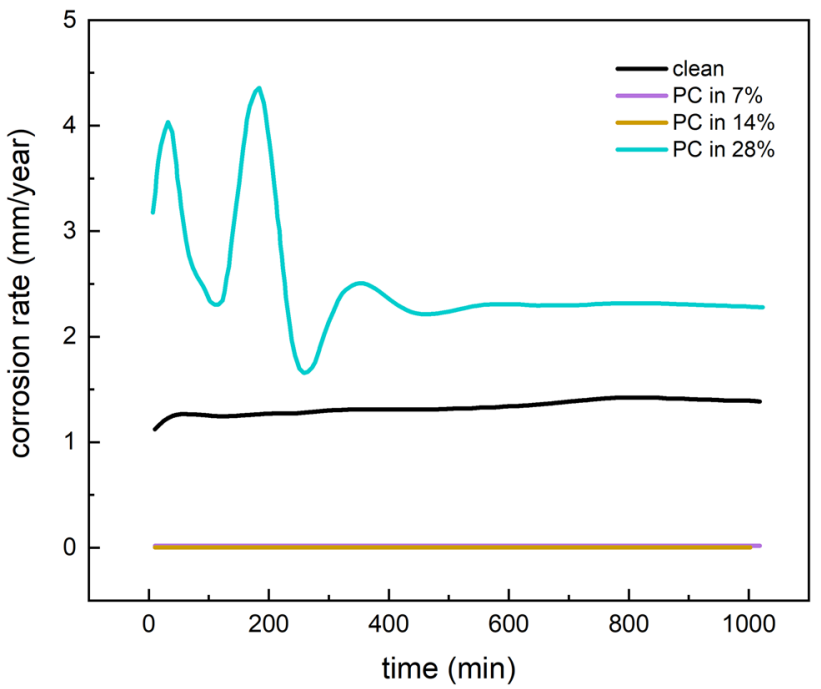

Fig. 14 Corrosion rate of the low alloy steels samples exposed to $3.5 \% \mathrm{NaCl} \mathrm{CO}$ saturated water following pre-corrosion in solutions of 7, 14 and $28 \% \mathrm{NaCl} \mathrm{CO}$ saturated water compared to sample without pre-corrosion over $1025 \mathrm{~min}$ of exposure time

the presence of ferrous oxides and $\mathrm{Cr}_{2} \mathrm{O}_{3}$. This may indicate layer breakdown has reached and exposed the surface of the metal.

\subsection{Corrosion Performance of Pre-corroded LAS}

As seen above LAS in the high salinity environments developed films that appear stable. In order to further examine the stability and corrosion protection potential of those films, LAS samples previously pre-corroded (PC) at salinities 7, 14 and $28 \% \mathrm{NaCl}$ were subjected to tests once again following the same protocol. The secondary set of tests was conducted in $3.5 \% \mathrm{NaCl}$ solution. The corrosion performance results of the PC specimens were compared to that of a clean surface specimen.

The following results in Fig. 14 show the progression of corrosion rate of a clean surface specimen and PC specimens in a $3.5 \%$ salinity environment. Effect on the corrosion rate of a metal in $3.5 \% \mathrm{NaCl} \mathrm{CO}_{2}$ saturated water when it has been pre-corroded in $\mathrm{CO}_{2}$ water of higher salinities 7, 14 and $28 \% \mathrm{NaCl}$.

For the pre-corroded LAS specimens in the 7 and $14 \%$ $\mathrm{NaCl}$ solutions, the measured corrosion rate is negligible and indistinguishable between the two in the plotted graph. The 7 and $14 \% \mathrm{NaCl}$ pre-corroded exhibit an average corrosion rate of $2.91 \times 10^{-7}$ and $2.42 \times 10^{-6} \mathrm{~mm} /$ year, respectivelya vast reduction compared to the $1.29 \mathrm{~mm} /$ year average for an untreated sample-achieving near complete protection.

Surprisingly, pre-corroding the LAS specimen in the $28 \% \mathrm{NaCl} \mathrm{CO}_{2}$ saturated solution, caused an increase in corrosion rate to an average of $2.65 \mathrm{~mm}$ /year. Furthermore, 
as seen in Fig. 14 the corrosion rate was volatile for the first $300 \mathrm{~min}$ in contrast to the other specimens which further indicates the lack of passivation. A stable state is then reached after $300 \mathrm{~min}$ exposure time and follows the same behaviour as the untreated sample although at an increased rate-indicating a level of protection has been achieved by the exposure to the $3.5 \% \mathrm{NaCl}$ solution.

Gravimetric corrosion rates were obtained for samples post-test and compared to the corrosion rates obtained from the broad-range destructive LPR sweeps.

As seen in Fig. 15 there are major discrepancies between the gravimetric and electrochemical data, with gravimetric corrosion rate being consistently higher. Such discrepancy can be attributed to the removal of fragile film during the post-test rinsing or simply due to the inaccuracy of the potentiostat when it comes to measuring corrosion rate where thick films are in place.

Both the 7 and 14\% PC specimens yield a significantly lower corrosion rates in comparison to the untreated LAS specimen.

Based on the gravimetric results, the 7 and $14 \%$ PC specimen showed the best performance by lowering the corrosion rate from $12.54 \mathrm{~mm} /$ year, for the untreated sample, to $2.18 \mathrm{~mm} /$ year and $2.9 \mathrm{~mm} /$ year, respectively.

By contrast, the corrosion rate for the $28 \%$ PC specimen increased to $16.6 \mathrm{~mm} /$ year for the untreated sample. However, what is very impressive is that the corrosion resistance of the 7 and 14\% PC LAS specimens was not only superior to the clean LAS specimens but also superior to $13 \mathrm{Cr}$ and $\mathrm{S} 13 \mathrm{Cr}$ (see Fig. 8). Namely, the gravimetric corrosion rates of $13 \mathrm{Cr}$ and $\mathrm{S} 13 \mathrm{Cr}$ were 5.7 and 4.4 times higher than the 7\% PC and 4.3 and 3.3 times higher than the $14 \% \mathrm{PC}$ corrosion rates, respectively.

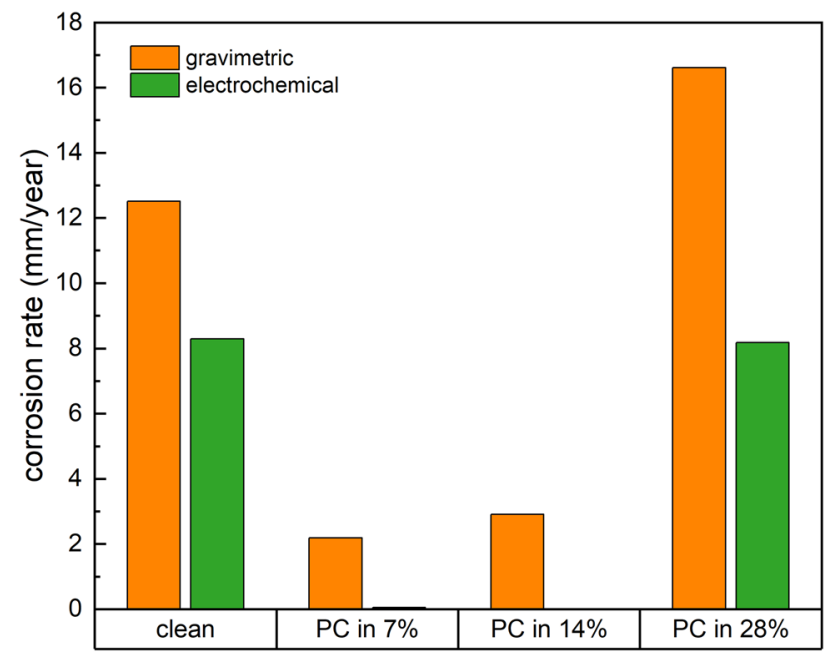

Fig. 15 Electrochemical corrosion rate vs. Gravimetric corrosion rate for 7, 14 and $28 \% \mathrm{NaCl}$ pre-corroded samples in $3.5 \% \mathrm{NaCl}$ as well as untreated sample in $3.5 \% \mathrm{NaCl}$ solutions

\subsection{Cross-Sectional Analysis}

The extremely low corrosion rates recorded for the 7 and $14 \% \mathrm{NaCl}$ pre-corroded samples in $3.5 \% \mathrm{NaCl}$ solution tests warranted a closer inspection. The specimens were cut and mounted in Bakelite with the cut face polished to a mirror finish in preparation for cross-sectional analysis.

The SEM analysis shows large disruption to the $\mathrm{FeCO}_{3}$ layer, indicated by the dark grey areas, and LAS surface, indicated by the light grey areas, for both specimens due to cutting and polishing, seen in Fig. 16a, c. However, even with the disruption some interesting observations can be made. As seen in Fig. $16 \mathrm{~b}$ at $\times 5.0 \mathrm{k}$ magnification, in the $7 \%$ $\mathrm{NaCl} \mathrm{PC}$ sample, the $\mathrm{FeCO}_{3}$ layer, as confirmed by EDS, close to the metal surface appears to have a dense structure and it only becomes porous as we move further away from the LAS surface.

For the $14 \% \mathrm{NaCl} \mathrm{PC}$ sample, seen in Fig. 16d, the protective $\mathrm{FeCO}_{3}$ layer appears uniformly porous. The more porous appearance of the $\mathrm{FeCO}_{3}$ layer, indicative of poorer mechanical properties and adhesion, may be a result of the reduced availability of $\mathrm{CO}_{2}$ during film formation caused by the higher salinity and therefore greater salting out effect.

\section{Discussion}

For $13 \mathrm{Cr}$, the increase of salinity to $0.16,0.35$ and $3.5 \%$ resulted in a corrosion rate lower than the one witnessed for $0 \% \mathrm{NaCl}$. This can be attributed to the more electrochemically active environment helping $13 \mathrm{Cr}$ to form and sustain a protective chromium oxide layer which eventually leads to the passivation of the specimen surface. This agrees with the findings of Crolet, [21] who noted the benefits of $13 \mathrm{Cr}$ to decrease the corrosion rate significantly by means of alloys constituents which decreased the time at which passivity was achieved. However, when the environment becomes overly corrosive, much like when the salinity was increased to $28 \%$ $\mathrm{NaCl}$ or at $3.5 \%$ salinity accompanied by the anodic polarisation, the protective chromium oxide film breaks locally exposing the surface to the environment which causes the formation of pits.

The corrosion rate of $\mathrm{S} 13 \mathrm{Cr}$ much like $13 \mathrm{Cr}$ starts high and over time due to the formation of a protective oxide film is reduced but when the salinity is increased to $28 \%$ the corrosion trend becomes volatile and unpredictable due to repeated attempts at oxide film formation followed by localised film collapsing. $\mathrm{Cl}^{-}$ions are drawn towards the iron cations produced during surface breakdown within the pit region-becoming a self-sustaining degradation process. Longer exposure time would be required to evaluate if the surface film can eventually prevent localised attacks and achieve stability. Those localised attacks and pit formation 
Fig. 16 Oxide layer morphology of $7 \% \mathrm{NaCl}$ PC LAS at $\times 1.0 \mathrm{k}$ magnification $(\mathbf{a})$ and at $\times 5$.0k magnification (b) and oxide layer morphology of $14 \% \mathrm{NaCl}$ PC LAS at $\times 1.0 \mathrm{k}$ magnification (c) and at $\times 5.0 \mathrm{k}$ magnification (d)

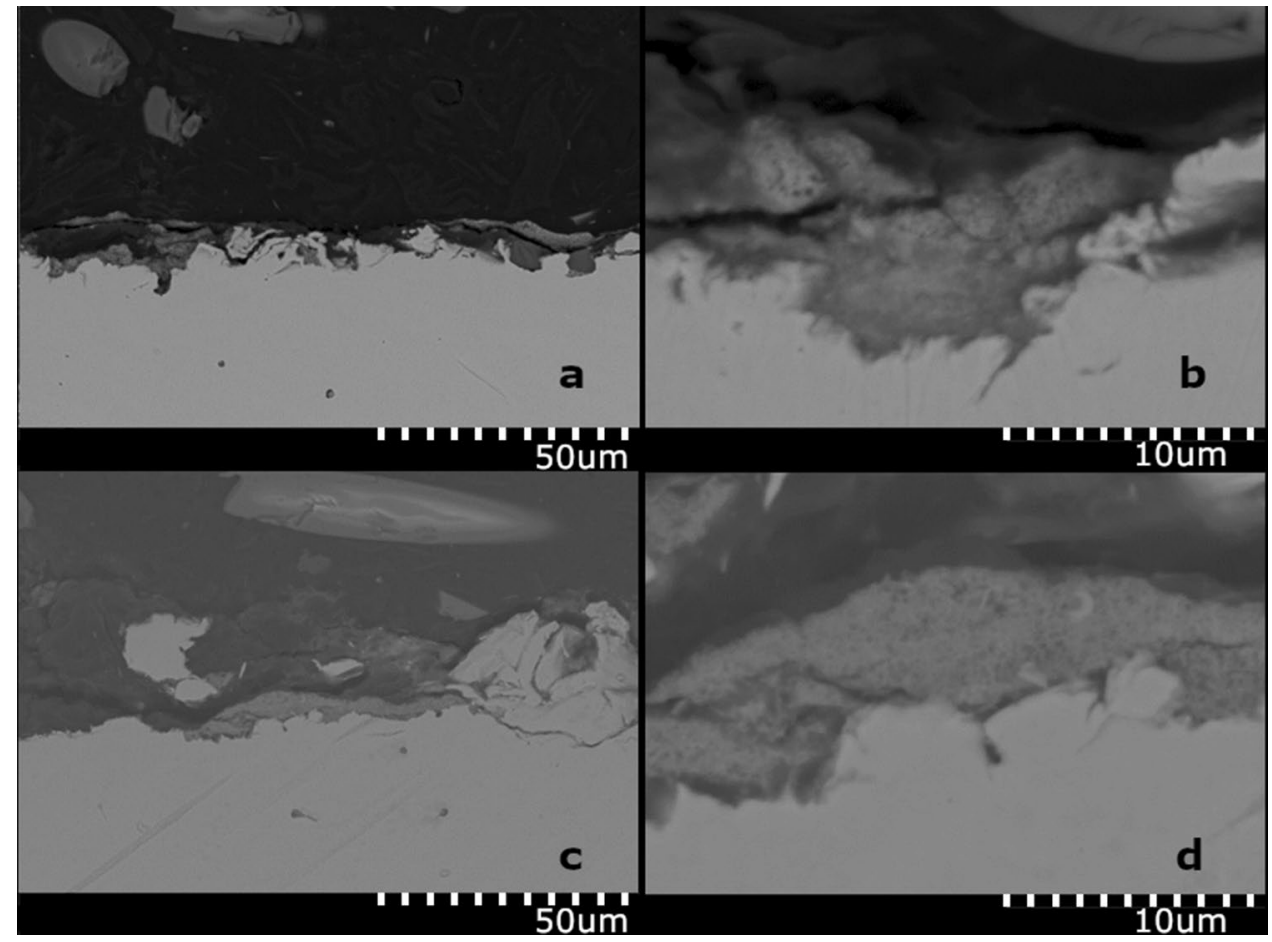

the tested salinity range. This is thought to be as a result of $\mathrm{FeCO}_{3}$ precipitation - confirmed by EDS—witnessed posttest on the sample surface which restricts the electrochemical readings leading to greater gravimetric corrosion rate.

SEM analysis revealed the development of a black $\mathrm{FeCO}_{3}$ layer whose stability and thickness increased as salinity was increased. However, the $\mathrm{FeCO}_{3}$ layer showed signs of degradation as the salinity increased to 14 and $28 \%$. Artificially formed films have been used for the corrosion protection of metal surfaces [26]. The protective properties of the films developed in high salinity environments (7, 14 and 28\%) were put to test in $3.5 \%$ salinity, $\mathrm{CO}_{2}$ saturated environment to examine their suitability as corrosion inhibitors. Both the 7 and $14 \%$ pre-corroded specimens showed excellent corrosion resistance; however, the corrosion rate values for the $7 \%$ were slightly better which can be attributed to the higher quality uniform film with no signs of degradation priorly formed in the more favourable environment, with high enough salinity to allow the accelerated layer growth but not high enough to be detrimental to the availability of $\mathrm{CO}_{2}$ for $\mathrm{FeCO}_{3}$ precipitation on the surface.

Cross-sectional analysis of the $7 \% \mathrm{NaCl}$ pre-corroded sample displayed a dense layer formation at the metal surface $/ \mathrm{FeCO}_{3}$ interface which became porous as the distance from the metal surface increased. The $14 \% \mathrm{NaCl}$ pre-corroded sample displayed a uniformly porous $\mathrm{FeCO}_{3}$ layer formed on the LAS surface.

The $28 \%$ PC specimen showed increased corrosion rate of a volatile nature over the first $400 \mathrm{~min}$ of exposure. This is thought to be a result of the poorly formed layer with sites 
where corrosion could jumpstart, as witnessed by SEM. The poor layer properties are a result of the salting out effect which restricts the availability of $\mathrm{CO}_{2}$ needed to create a stable protective layer of $\mathrm{FeCO}_{3}$ in high salinities. Both layer breakdown and regrowth contribute to these fluctuations in corrosion rate before stability is achieved.

\section{Conclusions}

The corrosion resistance of LAS, $13 \mathrm{Cr}$ and $\mathrm{S} 13 \mathrm{Cr}$ was investigated. The metals under examination were subjected to a number of tests with varying salinity that look at the corrosion behaviour over time and the corrosion resistance under anodic polarisation. The results revealed that increasing salinity causes an increase in corrosion rate up a limiting value after which further salinity increase causes a decrease in corrosion rate. The salinity value at which corrosion rate picks has a multiparametric dependancy. In the case of LAS it reached peak corrosion at 3.5\% salinity but when anodically polarised corrosion peaked at $14 \%$ salinity.

Both $13 \mathrm{Cr}$ and $\mathrm{S} 13 \mathrm{Cr}$ display low rates of corrosion compared to LAS with less noble chemical composition. However, the superior chemical composition didn't not negate the effect of corrosion in high salinity environments when anodically polarised with $13 \mathrm{Cr}$ displaying higher electrochemical and gravimetric corrosion rates than LAS in $28 \%$ salinity environments. The sever degradation observed in $13 \mathrm{Cr}$ and $\mathrm{S} 13 \mathrm{Cr}$ in high salinities was in the form of localised pitting caused by protective chromium oxide layer breakdown.

The surface morphology of the $\mathrm{FeCO}_{3}$ layer formed on LAS under 7\% and 14\% $\mathrm{NaCl}$ conditions shows superior properties, being compact in appearance with minimal cracks in the formed plates witnessed. From cross-sectional analysis, $7 \% \mathrm{NaCl}$ pre-corroded sample demonstrates superior internal layer properties, displaying densely formed $\mathrm{FeCO}_{3}$ at the metal surface compared to uniformly porous layers witnessed at other salinities. The stability of the protective film was then put to test by subjecting specimens, that were already corroded in 7, 14 and $28 \% \mathrm{NaCl}$ solutions, to a corrosion test in a $3.5 \% \mathrm{NaCl}$ environment.

Both 7 and $14 \% \mathrm{NaCl}$ pre-corroded samples show excellent reduction in corrosion rate when tested in seawater environment of $3.5 \% \mathrm{NaCl}$. The $7 \% \mathrm{NaCl}$ pre-corroded sample produces the optimum decrease of corrosion rate from 12.54 to $2.18 \mathrm{~mm} /$ year when compared to a non-pre-corroded sample-a reduction of $82.6 \%$. It is thought that the $7 \% \mathrm{NaCl}$ pre-corroded sample displays excellent potential for protecting the low alloy steel steel in seawater environments. The balance between increased conductivity and reduced "salting out" effect provide an environment which both accelerates the formation of $\mathrm{FeCO}_{3}$ as well as providing an abundance of $\mathrm{CO}_{2}$ to form a dense, stable and protective layer. It would significantly reduce capital and operating costs if the corrosion resistance of less noble alloys such as LAS could be enhanced to levels surpassing those of chromium rich alloys by simple environmental manipulation.

Acknowledgements The authors are grateful for the support of BP plc and Energy Technology Partnership Scotland.

\section{Compliance with Ethical Standards}

Conflict of interest On behalf of all authors, the corresponding author states that there is no conflict of interest.

Open Access This article is licensed under a Creative Commons Attribution 4.0 International License, which permits use, sharing, adaptation, distribution and reproduction in any medium or format, as long as you give appropriate credit to the original author(s) and the source, provide a link to the Creative Commons licence, and indicate if changes were made. The images or other third party material in this article are included in the article's Creative Commons licence, unless indicated otherwise in a credit line to the material. If material is not included in the article's Creative Commons licence and your intended use is not permitted by statutory regulation or exceeds the permitted use, you will need to obtain permission directly from the copyright holder. To view a copy of this licence, visit http://creativecommons.org/licenses/by/4.0/.

\section{References}

1. Revie RW (2011) Uhlig's corrosion handbook, 3rd edn. Wiley, Hoboken

2. Simmons MR (2008) Oil and gas "rust": an evil worse than depletion. In: Offshore technology conference (OTC) presentation: NACE International Oil and Gas Production

3. Hedges B, Chen HJ, Bieri TH, Sprague K (2006) A review ofmonitoring and inspection techniques for $\mathrm{CO}_{2}$ and $\mathrm{H} 2 \mathrm{~S}$ corrosionin oil \& gas production facilities: location, location, location.. In: Corrosion 2006. NACE International

4. Tunio SQ, Tunio AH, Ghirano NA, Adawy ZM (2011) Comparison of different enhanced oil recovery techniques for better oil productivity. Int J Appl Sci Technol 1:143-153

5. National Association of Corrosion Engineers \& American Petroleum Institute (1958) Corrosion of oil- and gas-well equipment, 1 st edn. Harropian Books, Dallas, Texas

6. Waldrip HE (1948) Present day aspects of condensate well corrosion. Corrosion 4:611-618. https://doi. org/10.5006/0010-9312-4.12.611

7. Fang H, Brown B, Nes S (2011) Effects of sodium chloride concentration on mild steel corrosion in slightly sour environments. Corrosion. https://doi.org/10.5006/1.3546847

8. Bilhartz HL (1952) Technical practices committee 1-corrosion in oil and gas well equipment. Corrosion 8:293-295. https://doi. org/10.5006/0010-9312-8.9.293

9. De Waard C, Milliams DE (1975) Carbonic acid corrosion of steel. Corrosion 31:177-181. https://doi. org/10.5006/0010-9312-31.5.177

10. Nafday $\mathrm{O}$, Nesic $\mathrm{S}$ (2005) Iron carbonate scale formation and $\mathrm{CO}_{2}$ corrosion in the presence of acetic acid. In: Corrosion 2005. NACE International, Houston, TX, p 27 
11. Videm K, Dugstad A (1989) Corrosion of carbon steel in an aqueous carbon dioxide environment part 2: film formation. Mater Perform 28:36-67

12. Nesic S, Lee K-LJ (2003) A mechanistic model for carbon dioxide corrosion of mild steel in the presence of protective iron carbonate films part 3: film growth model. Corrosion 59:13

13. Zekos I, Stack MM (2019) A note on a design protocol for deoxygenation of water. Electrochem Commun 103:12-16. https ://doi.org/10.1016/j.elecom.2019.04.009

14. API (2018) API-5CT, casing and tubing specification, 10th edn. American Petroleum Institute, Washington, D.C.

15. Barnartt S (1952) Primary current distribution around capillary tips used in the measurement of electrolytic polarization. $\mathrm{J}$ Electrochem Soc 99:549-553. https://doi.org/10.1149/1.27796 50

16. Pletcher D, Greff R, Robinson J (2001) Instrumental methods in electrochemistry. Woodhead Publishing, Cambridge

17. ASTM International (2014) ASTM standard G5-14 standard reference test method for making potentiodynamic anodic polarization measurements. ASTM International, West Conshohocken, PA

18. Alcántara J, de la Fuente D, Chico B et al (2017) Marine atmospheric corrosion of carbon steel: a review. Materials (Basel) 10:406. https://doi.org/10.3390/ma10040406

19. Dugstad A (2006) Fundamental aspects of $\mathrm{CO}_{2}$ metal loss corrosion-part 1: mechanism. In: Corrosion 2006. NACE International, Houston, TX, p 18

20. Li H, Li D, Zhang L et al (2019) Passivity breakdown of $13 \mathrm{Cr}$ stainless steel under high chloride and $\mathrm{CO}_{2}$ environment. Int J Miner Metall Mater 26:329-336. https://doi.org/10.1007/s1261 3-019-1741-9
21. Crolet J-L (1983) Acid corrosion in wells $\left(\mathrm{CO}_{2}, \mathrm{H} 2 \mathrm{~S}\right)$ : metallurgical aspects. J Pet Technol 35:1553-1558. https://doi. org/10.2118/10045-PA

22. Sunaba T, Meng H, Tomoe Y, Watanabe T (2009) Corrosion experience of $13 \% \mathrm{Cr}$ steel tubing and laboratory evaluation of super $13 \mathrm{Cr}$ steel in sweet environments containing acetic acid and trace amounts of H2S. In: Corrosion 2009. NACE International, Atlanta, Georgia, p 10

23. Akimov GV (1959) Factors influencing corrosion. Corros Natl Assoc Corros Eng 15:23-35. https://doi.org/10.1002/9781118737 880.ch2

24. Zeng Z, Lillard RS, Cong $\mathrm{H}$ (2016) Effect of salt concentration on the corrosion behavior of carbon steel in $\mathrm{CO}_{2}$ environment. Corrosion 72:805-823. https://doi.org/10.5006/1910

25. Zhang X, Zhang L, Jin T et al (2017) Salting-in/salting-out mechanism of carbon dioxide in aqueous electrolyte solutions. Chin J Chem Phys 30:811-816. https://doi.org/10.1063/1674-0068/30/ cjep1711230

26. Shen X, Cheng X, Shi P et al (2019) Lithium-matrix composite anode protected by a solid electrolyte layer for stable lithium metal batteries. J Energy Chem 37:29-34. https://doi.org/10.1016/j. jechem.2018.11.016

Publisher's Note Springer Nature remains neutral with regard to jurisdictional claims in published maps and institutional affiliations. 